\title{
Hidden costs of mental illness ${ }^{\dagger}$
}

\author{
MARTIN KNAPP
}

That mental health problems have major impacts on disability, mortality and health care systems has never been in doubt. Disability-adjusted life-years, standardised mortality rates and health care costs have all been used to aggregate these impacts see, for example, the report by the World Health Organization (2001). However, what is frequently overlooked is a number of often substantial economic consequences, sometimes referred to as the indirect costs. These costs fall to the social care, education, housing, criminal justice and social security systems, and often they are especially felt by individuals with mental health problems and their families.

\section{DEPRESSION: SERVICE USE AND EMPLOYMENT}

Thomas \& Morris (2003, this issue) describe some of these indirect costs, estimating that the effect of depression on employment (and hence on national productivity) in cost terms is 23 times larger than the costs falling to the health service. This is an enormous 'hidden' impact, but even so it is potentially an underestimate. The study was confined to adults, and related only to people whose depression had been diagnosed (when we know that much depression goes untreated), and it excluded social care and social security costs (rightly, in the latter case, for the purposes of a cost-of-illness calculation, but taxpayers might nevertheless like to know how much depression is costing them in transfer payments through the tax and national insurance systems). On the other hand, the study employs a human capital approach to the costing of lost employment, which is known to generate quite high estimates of what is always a difficult economic consequence to value. Despite

†See pp. 514-519, this issue. these almost inevitable limitations, Thomas $\&$ Morris not only provide detailed accounts of the health service costs, but helpfully remind us that the implications of depression range much further afield.

Three other recent studies - two in the USA, one in the UK - provide further intelligence on the links between depression and employment. Almond \& Healey (2003) show that (self-reported) depression/ anxiety is the single most important cause of workplace absenteeism in the UK. Kessler et al (2001) described the hidden impact of depression on reduced productivity at work - an impact that will not be adequately measured by absenteeism rates. Third, there is evidence that remission of depressive symptoms more rapidly affects employment status than health service utilisation (Simon et al, 2000). Although usually discussed in terms of lost national productivity, the employment effects of depression are most immediately felt by people with the illness. For most people, employment is not only their major source of income and pension entitlements (and perhaps various fringe benefits), but also generates self-esteem, gives social identity and expands social networks.

\section{OTHER MENTAL HEALTH PROBLEMS}

Sizeable 'hidden' costs are not unique to depression. In a small sample study of children with conduct disorder we found that only one-sixth of the total cost was carried by the health service, the remainder falling to schools (special educational needs), social care agencies, families (disrupted parental employment, household damage) and the welfare system (disability and similar transfer payments) (Knapp et al, 1999). Another study found that adults who as children had conduct disorder generated costs for a range of agencies that were significantly higher than the costs for a non-morbid control group; most noticeable were the criminal justice system costs, which were 18 times greater (Scott et al, 2001). Not surprisingly, the British Government's imminent new initiatives to tackle antisocial behaviour include targeting behavioural problems in childhood. Crime costs are another important consideration when looking at the social impact of addictions. For every $£ 1$ of health service expenditure on people referred for addiction treatment, it has been calculated that another $£ 3$ is incurred by the criminal justice system and $£ 10$ by the victims of crime (Healey et al, 1998). In old age, mental health problems can often lead to expensive admissions to nursing homes, but a bigger impact is often felt in the family. Although it is difficult to put an economic value on informal care, there is no doubt that the cost is both high and often overlooked in policy and practice discussions (McDaid, 2001).

On the other hand, although some people with mental health problems have quite wide-ranging needs, in simple cost terms the lion's share might still fall to the health service. Calculations for people aged 18-65 years with psychoses supported by either intensive or standard case management in the UK700 trial indicated that two-thirds of the total cost fell to the health service (Byford et al, 2000), and this pattern has been replicated in other studies.

\section{WHAT NEEDS TO BE DONE?}

These often substantial non-health care costs are not decorative embellishments in obscure academic studies. Nor are they the chartings of obsessional researchers intent on costing anything and everything. They are real burdens on resources which have to be carried by some individual or some part of society. Productivity losses for the economy are worrying, but the associated earnings loss for people with depression could be devastating. Higher criminal justice system costs could mean higher taxes for all of us, but for the victims of heroin-seeking crime the consequences could be both inconvenient and traumatic.

What do we need to do? First, most predictably, we need studies like that reported by Thomas \& Morris to tell us the full size and scope of the economic impact of an illness. We do not want too many of them, however, because such cost-of-illness calculations merely describe what is, not what 
we should do about it, let alone providing guidance to decision-makers on how to get the best out of their limited resources. For the latter we need cost-effectiveness and similar evaluations that combine costs with outcomes data. The problem, however, is that too many such evaluations are rather narrow in their measurement of costs (and often of outcomes, in fact). Most industry-funded drug trials are driven by the anticipated needs of the professionals and agencies who will potentially buy their products, which usually results in the collection only of 'medical service costs'. The National Institute for Clinical Excellence is in danger of encouraging lessthan-comprehensive cost and outcome measures because it is charged with advising the National Health Service (NHS), not the Exchequer - let alone the whole of the UK economy (Oliver et al, 2002). Better research will help, but will change nothing on its own. At practice level, care professionals already take into account some of the non-health-care impacts of mental illness, for example when factoring into their decision-making a patient's ability to return to work. However, as performance assessment not only becomes more prevalent but also brings rewards and sanctions (with 'star ratings' for NHS trusts feeding directly into resource allocations and determining clinical autonomy, for example), such professionals may find it harder and harder to take decisions that protect somebody else's budget (including the patient's) if it is at the cost of their own agency's resources. Child and adolescent mental health services will do what they can to treat behavioural problems - within their available resources - but if the biggest economic return to the successful treatment of conduct disorder in the long run is enjoyed by the criminal justice system, is there not a case for the Home Office to fund parent management training? This is the nub of the problem. Research can only describe and sometimes guide, and treatment professionals and their employing organisations

MARTIN KNAPP, PhD, Centre for the Economics of Mental Health, PO Box 24, David Goldberg Centre, Institute of Psychiatry, Denmark Hill, De Crespigny Park, London SE5 8AF, and London School of Economics, London, UK

(First received 21 May 2003, accepted 16 June 2003)

can only do as much as their budgets (and performance assessment frameworks) will allow. Effective action can only really be taken at governmental level (and that usually means at a level above individual government departments) to address the perverse incentives that otherwise stop agencies from pursuing what is best for patients at a cost that is most efficient to society.

Governments particularly need to recognise the distributional consequences of different mental health policies on practices. Cholinesterase inhibitors that slow down cognitive decline of people with Alzheimer's disease sufficiently to delay admission to a nursing home or hospital will save a government money in terms of treatment costs (and also hotel costs for low-income patients), but will then mean that the responsibilities (economic and otherwise) of family carers will continue for longer. Families may want to have their loved ones living with them, and certainly could benefit from their relative being less confused and dependent, but they might also find themselves drained by these continuing caring responsibilities. More generally, if mental illness is more prevalent in lower-income groups (whatever the patterns of cause and effect) and if (hidden) individual and family costs are ignored when policy or practice changes are introduced - or indeed when potential new developments are turned down - is this not adding to the social exclusion of already marginalised groups? People with mental health problems often have a broad range of needs; it is imperative that costing of their care is similarly broad if policy and practice are to improve in terms of both their efficiency and distributional consequences.

\section{DECLARATION OF INTEREST}

None.

\section{REFERENCES}

Almond, S. \& Healey, A. (2003) Mental health and absence from work. Work, Employment and Society, 17 in press.

Byford, S., Fiander, M., Torgerson, D. J., et al. (2000)

Cost-effectiveness of intensive $v$. standard care management for severe psychotic illness: UK700 case management trial. British Journal of Psychiatry, I76, 537-543.

Healey, S., Knapp, M., Astin, J., et al (1998) Economic burden of drug dependency: social costs incurred by drug users at intake to the National Treatment Outcome Research Study. British Journal of Psychiatry, 173, 160-165.

Kessler, R. C., Greenberg, P. E., Mickelson, K. D., et a (200I) The effects of chronic mental health conditions on work loss and work cut back. Journal of Occupational and Environmental Medicine, 43, 218-225.

Knapp, M., Scott, S. \& Davies, J. (1999) The cost of antisocial behaviour in younger children. Clinical Child Psychology and Psychiatry, 4, 457-473.

McDaid, D. (200I) Estimating the costs of informal care for people with Alzheimer's disease: methodological and practical challenges. International Journal of Geriatric Psychiatry, 16, 400-405.

Oliver, A. Healey, A. \& Donaldson, C. (2002) Choosing the method to match the perspective: economic evaluation and its implications for health services efficiency. Lancet, 359, 177I-1774.

Scott, S., Knapp, M., Henderson, J., et al (200I) Financial cost of social exclusion: follow-up study of antisocial children into adulthood. BM|, 323, 191-194.

Simon, G., Revicki, D., Heiligenstein, J., et al (2000) Recovery from depression, work productivity, and health care costs among primary care patients. Generol Hospital Psychiatry, 22, 153-162

Thomas, C. M. \& Morris, S. (2003) Cost of depression among adults in England in 2000. British Journal of Psychiatry, 183, 514-519.

World Health Organization (200I) World Health Report. Geneva: WHO. 